\title{
References
}

Migliori GB, Sotgiu G, Gandhi NR, et al. Drug resistance beyond extensively drug-resistant tuberculosis: individual patient data meta-analysis. Eur Respir J 2013.

2 Diel R, Loddenkemper R, Zellweger J-P, et al. Old ideas to innovate tuberculosis control: preventive treatment to achieve elimination. Eur Respir 2013; 42: 785-801.

3 Blasi F, Dara M, Van der Werf MJ, et al. Supporting TB clinicians managing difficult cases: the ERS/WHO Consilium. Eur Respir J 2013; 41: 491-494.

4 Sotgiu G, Centis R, D'Ambrosio L, et al. Efficacy, safety and tolerability of linezolid containing regimens in treating MDR-TB and XDR-TB: systematic review and meta-analysis. Eur Respir J 2012; 40: 1430-1442.

\section{Admissions and patterns of mechanical ventilation of critical COPD: an old and common friend, are we still prepared?}

\begin{abstract}
To the Editor:
Patients with chronic obstructive pulmonary disease (COPD) admitted to an intensive care unit (ICU) due to an acute exacerbation are still confronted with a substantial hospital mortality rate of $24 \%$ and worse clinical outcomes, respectively [1]. About 10\% of COPD patients are at high risk for prolonged mechanical ventilation and mortality ranges 55-78\% [2]. However, there is a paucity of long-term survival data regarding admissions and patterns of mechanical ventilation of critical COPD patients.
\end{abstract}

In their study, FunK et al. [3] describe the impact of mechanical ventilation strategies in patients with COPD exacerbations by means of a large epidemiological survey [3]. We consider that this is an important contribution to the knowledge of mechanical ventilation patterns, especially the subdivision into noninvasive ventilation (NIV) and invasive ventilation.

However, some characteristics of this study remained untested that could further consolidate their observations. We believe that some points investigated in this study are of interest that will allow a better understanding in future, especially if the following issues are taken into consideration.

First, the impact of alternatives other than that of NIV and decannulation on shortened and improved weaning from mechanical ventilation has yet to be verified $[4,5]$. Additionally, they did not consider common strategies that are based on tracheotomy.

Secondly, poor details on the aetiology of COPD exacerbations and comorbidities are given by the authors as follows: a) the presence of number of comorbidities may be of interest especially in reference to future epidemiology studies; b) physiological abnormalities at admission to ICU and development of nonrespiratory organ failure are important predictors of hospital outcome of critically ill patients with acute exacerbation of COPD (AE-COPD); and c) history of previous mechanical ventilation and ICU admissions should have been mentioned [5]. Additionally, the impact of increased age is discussed controversially. It is a known fact that the mortality rate of patients aged $\geqslant 65$ years doubles in 1 year, from $30 \%$ to $59 \%[6,7]$. Unfortunately, the current study lacks a strategy of how to manage this growing demand of elderly patients that need mechanical ventilation in the ICU. Normally, these patients suffer from poor nutritional status and low activities of daily living scores, which may both be further factors relevant to prolonged mechanical ventilation [8].

Thirdly, indications of NIV and IMV have not been clearly analysed. Especially the aspect of a so-called "learning curve" of NIV seems missing $[9,10]$. To be specific, the following aspects should be taken into account. a) Predictors of NIV failure: it would be interesting to know the risk for AE-COPD patients of having a second episode of acute respiratory failure after an initial (first $48 \mathrm{~h}$ ) successful response to NIV. This event is more likely to occur in patients with more severe functional and clinical disease, who are likely to have more complications at time of admission to ICU apart from a very poor in-hospital prognosis $[9,10]$. b) Admission source and NIV indications are not well specified in this survey that are commonly of 
relevance, to hospitals specifically for organisation models, such as the differentiation between respiratory ICU, step-down units or weaning respiratory units [10].

Fourthly, analysis of ICU beds and hospital costs in COPD is counterbalanced, and may be more efficiently balanced by a good efficiency of mechanical ventilation utilisation and ICU resources. Unfortunately, these considerations are a further aspect that is not well dealt with in this study. Respiratory high-dependence care units can, for example, provide full support especially for patients with single organ failure, which is more cost-effective than that of an ICU [10].

To conclude, we consider that epidemiological surveys are most wanted with a focus on identifying prognostic factors with ventilatory options and needs of these patients apart from optimising the organisational structures of an ICU. Currently, these are questions yet to be answered that may hopefully contribute to mechanical ventilation tools more effectively than those that are currently used. Thus, further epidemiological surveys are required and most welcomed to optimise mechanical ventilation of critically ill COPD patient.

0 @ERSpublications

Mechanical ventilation in COPD, more epidemiological studies are required http://ow.ly/mzJxh

Antonio M. Esquinas ${ }^{1}$ and Stein Markus ${ }^{2}$

${ }^{1}$ Intensive Care Unit, Hospital Morales Meseguer, Murcia, Spain. ${ }^{2}$ Respiratory Care Unit, Dept of Pneumology,

Landeskrankenhaus Natters, Natters, Austria.

Correspondence: A.M. Esquinas, Avenida Marques de Los Velez s/n, Murcia, 30008, Spain.

E-mail: antmesquinas@gmail.com

Received: Apr 302013 | Accepted: May 042013

Conflict of interest: None declared.

\section{References}

1 Ward NS, Dushay KM. Clinical concise review: Mechanical ventilation of patients with chronic obstructive pulmonary disease. Crit Care Med 2008; 36: 1614-1619.

2 Mohan A, Premanand R, Reddy LN, et al. Clinical presentation and predictors of outcome in patients with severe acute exacerbation of chronic obstructive pulmonary disease requiring admission to intensive care unit. BMC Pulm Med 2006; 6: 27.

3 Funk GC, Bauer P, Burghuber OC, et al. Prevalence and prognosis of COPD in critically ill patients between 1998 and 2008. Eur Respir J 2013; 41: 792-799.

4 Ceriana P, Carlucci A, Navalesi P, et al. Weaning from tracheotomy in long-term mechanically ventilated patients: feasibility of a decisional flowchart and clinical outcome. Intensive Care Med 2003; 29: 845-848.

5 Quinnell TG, Pilsworth S, Shneerson JM, et al. Prolonged invasive ventilation following acute ventilatory failure in COPD: weaning results, survival, and the role of noninvasive ventilation. Chest 2006; 129: 133-139.

6 Divo M, Cote C, de Torres JP, et al. Comorbidities and risk of mortality in patients with chronic obstructive pulmonary disease. Am J Respir Crit Care Med 2012; 186: 155-161.

7 Liu H, Zhang T, Ye J. Determinants of prolonged mechanical ventilation in patients with chronic obstructive pulmonary diseases and acute hypercapnic respiratory failure. Eur J Intern Med 2007; 18: 542-547.

8 Langlet K, Van Der Linden T, Launois C, et al. Predictive value of daily living score in acute respiratory failure of COPD patients requiring invasive mechanical ventilation pilot study. BMC Pulm Med 2012; 18, 12: 66.

9 Confalonieri M, Garuti G, Cattaruzza MS, et al. A chart of failure risk for noninvasive ventilation in patients with COPD exacerbation. Eur Respir J 2005; 25: 348-355.

10 Scala R, Corrado A, Confalonieri M, et al. Increased number and expertise of italian respiratory high-dependency care units: the second national survey. Respir Care 2011; 56: 1100-1107. 